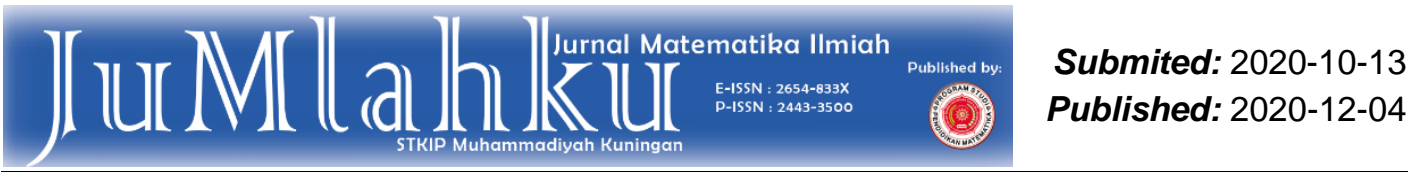

\title{
Pengintegrasian Budaya Lampung dalam Pembelajaran Mata Kuliah Himpunan Dengan Platform Schoology
}

Darwanto a), Karsoni Berta Dinata b), Junaidi c)

a,b,c) Universitas Muhammadiyah Kotabumi

$\underline{\text { dharwant@gmail.com }}{ }^{\mathrm{a})}, \underline{\text { karsoni.bertadinata@gmail.com }}{ }^{\mathrm{b}}$, junaidieljundi84@gmail.com ${ }^{\mathrm{b}}$ )

Article Info

Kaywords :Lokal Wisdom, Schoology, Piil Pesenggiri
Lampung has a wealth of cultural treasures that can be seen in the traditional Lampung house, Lampung traditional clothing, traditional musical instruments, Lampung traditional ceremonies, and the values of local wisdom of Lampung. To foster awareness and love of students towards Lampung culture, one way that can be done is by integrating Lampung culture with learning. The research method used is descriptive qualitative research method. Some of the cultural content of Lampung is integrated in the material of the association. In addition, the content of Lampung culture, especially the values of local wisdom of Lampung such as Piil Pesenggiri, Bejuluk adok, meet nyimah, nengah nyappukh, and Sakai Sambayan can also be integrated into association learning with the Schoology platform. 
Kata Kunci: Kearifan Lokal, Schoology, Piil Pesenggiri

\section{Abstrak}

Lampung memiliki khasanah kekayaan budaya yang dapat dilihat pada rumah adat lampung, Pakaian adat lampung, Alat-alat musik tradisional, Upacara adat Lampung, dan nilai-nilai kearifan lokal lampung. Untuk menumbuhkan kesadaran dan kecintaan mahasiswa terhadap budaya lampung, salah satu cara yang dapat dilakukan adalah dengan mengintegrasikan budaya lampung terhadap pembelajaran. Metode penelitian yang dilakukan adalah metode penelitian deskriptif Kualitatif. Beberapa konten budaya lampung dintegrasikan dalam materi himpunan. Selain itu juga, konten budaya lampung khususnya nilai-nilai kearifan lokal lampung seperti piil pesenggiri, bejuluk adok, nemui nyimah, nengah nyappukh, dan Sakai Sambayan dapat juga diintegrasikan dalam pembelajaran himpunan dengan flatform Schoology.

\section{PENDAHULUAN}

Lampung memilki khasanah kekayaan budaya yang semestinya dijaga dan dilestarikan oleh setiap warga Lampung khususnya, dan seluruh Warga Negara Indonesia pada umumnya. Sebagai upaya yang dapat dilakukan dalam menumbuhkan kesadaran dan kecintaan mahasiswa terhadap budaya lampung, salah satu cara yang dapat dilakukan adalah dengan mengintegrasikan budaya lampung terhadap pembelajaran himpunan dengan flatform schoology.

Himpunan merupakan salah satu mata kuliah yang diajarkan di program studi pendidikan matematika. Berdasarkan evaluasi internal, proses pembelajaran himpunan masih banyak yang perlu diperbaiki. Perbaikan Proses pembelajaran yang dilakukan secara terus menerus diharapkan akan semakin meningkatkan mutu pembelajaran kedepannya (Dinata, 2018).

Berbagai fenomena yang terjadi di sekitar kita dapat menjadi motivasi dosen dalam meningkatkan kualitas pembelajaran. Salah satu fenomena yang tampak saat ini adalah bahwa hampir semua mahasiswa memiliki smartphone. Penggunaan smartphone oleh mahasiswa harus diarahkan dan dimanfaatkan sebagai alat untuk mendukung keberhasilan pembelajaran. Mengingat perkembangan laju teknologi informasi yang demikian sangat cepat dikalangan mahasiswa harus termanfaatkan secara optimal untuk mencapai tujuan pembelajaran khususnya mata kuliah himpunan. Juraman menyarankan bahwa "kiranya dengan hadirnya smartphone di kalangan mahasiswa dapat menunjang aktivitas belajar mahasiswa" (Juraman, 2014).

Penggunaan smartphone oleh mahasiswa dalam kaitanya dengan pembelajaran biasanya untuk hal-hal seperti membantu mahasiswa dalam mengakses sumber ajar, pemanfaatan sosial media (WhatsApp, Gmail, dan lainlain) untuk komunikasi dan tukar menukar referensi (misalkan Ppt, lembar tugas, dan lain-lain), menghubungi dosen ketika tidak masuk atau menanyakan suatu informasi. Penelitian yang dilaksanakan oleh Timbowo menyatakan bahwa "penggunaan 
smartphone oleh mahasiswa lebih banyak digunakan sebagai media komunikasi" (Timbowo, 2016). Selain itu juga smartphone oleh mahasiswa juga banyak digunakan untuk mengakses informasi edukasi (Juraman, 2014).

Pemanfaatan teknologi informasi dikalangan mahasiswa tentu saja perlu lebih dioptimalkan untuk mencapai kesuksesan belajar mahasiswa. Perlu sebuah platform berbentuk Learning Manajemen System (LMS) yang mampu memfasilitasi dan mempermudah mahasiswa belajar. Salah satu platform yang sudah ada tetapi belum digunakan di prodi Pendidikan Matematika Universitas Muhammadiyah Kotabumi adalah schoology. Aminoto menyebutkan bahwa "terdapat peningkatan hasil belajar siswa setelah diterapkan media e-learning berbasis Schoology" (Aminoto \& Pathoni, 2014). Penelitian yang dilakukan oleh Wahyudi yang mengembangkan Pembelajaran Fisika SMA Berbasis ELearning Dengan Schoology bahwa produk pengembangan layak, mudah digunakan dan bermanfaat (Wahyudi, 2017). Oleh karena itu Pemanfaatan Schoology dalam proses pembelajaran himpunan diharapkan akan meningkatkan keberhasilan belajar mahasiswa.

Schoology adalah jejaring sosial berbasis web khusus yang difokuskan pada kerjasama, untuk memungkinkan pengguna membuat, mengelola, dan saling berinteraksi serta berbagi konten akademis. Schoology memberikan akses pada dosen dan mahasiswa untuk presensi, pengumpulan tugas, latihan soal dan media sumber belajar yang bisa diakses kapanpun dan dimanapun serta juga memberikan akses kepada orang tua mahasiswa untuk memantau proses belajar mahasiswa. Melalui pemanfaatan Schoology dalam pembelajaran mata kuliah himpunan diyakini akan sangat membantu mahasiswa dalam belajar himpunan.

Perlu diperhatikan bahwa Universitas Muhammadiyah Kotabumi memiliki pola ilmiah pokok atau warna keilmuan yaitu mengintegrasikan kearifan lokal lampung dalam setiap kegiatan Tridharma Perguruan Tinggi. Oleh karena itu perlu adanya pengintegrasian Budaya Lampung dalam pengembangan pembelajaran mata kuliah himpunan dengan basis teknologi berplatform schoology. Hal ini juga sebagai salah satu pengembangan soft skills pendidik dan peserta didik dalam pembelajaran (Darwanto \& Sari, 2020).

Pengintegrasian Budaya Lampung dalam pembelajaran akan berdampak sangat baik bagi mahasiswa. Mahasiswa akan lebih mengenal budaya disekitarnya dan lebih mencintai budaya Lampung sebagai salah satu khasanah kekayaan Budaya Negara Republik Indonesia. Musafiri menyatakan integrasi nilai-nilai kearifan lokal berdampak pada penguatan karakter peserta didik (Musafiri, 2016). Selain itu jika mahasiswa memahami lebih mendalam terkait Budaya Lampung, mahasiswa akan mengerti dan menyadari akan nilai-nilai luhur Budaya Lampung yang tertuang dalam Kearifan Lokal Lampung yaitu piil pesenggiri dan muakhi. Penghayatan terhadap piil pesenggiri dan muakhi akan melahirkan generasi yang berakhlak dan berwawasan islami.

Penelitian yang dilakukan oleh Dwidayati menyebutkan berbagai bentuk 
etnomatematika dari suatu budaya tertentu seperti bangunan cagar budaya maupun noncagar budaya serta makanan tradisional memiliki relasi dengan konsep-konsep matematika seperti bangun datar, bangun ruang, himpunan, simetri, statistika, dan aritmetika sosial dapat diintegrasikan dalam proses pembelajaran" (Dwidayati, 2018). Lebih lanjut, Dwidayati menyatakan bahwa pengintegrasian etnomatematika dapat dioptimalkan melaui pembelajaran berbasis masalah. Prihatini menyebutkan "pengintegrasian budaya lokal dapat diintegrasikan dalam buku pelajaran" (Prihatini, 2015). Dalam penelitian ini, bentuk pengintegrasian budaya lokal dilakukan dengan mengintegrasikan Budaya lampung dalam konten buku ajar Himpunan. Cara mengintegrasikannya dilakukan dengan membuat permasalahan budaya lampung terkait dengan himpunan. Tentu saja permasalahan dibuat sesuai dengan level sarjana. Adapun bentuk pengintegrasian budaya lampung dalam pembelajaran himpunan berbasis schoology adalah dengan melaksanakan pembelajaran berbasis masalah. Setelah dijelaskan konsep himpunan mahasiswa diarahkan untuk memecahkan masalah himpunan terkait budaya lampung.

\section{METODE}

Tujuan dari penelitian ini adalah 1) Bagaimana mengintegrasikan budaya lampung kedalam buku ajar himpunan, 2) Bagaimana mengintegrasikan budaya lampung ke dalam pembelajaran himpunan dengan Platform schoology. Untuk mencapai tujuan tersebut, metode penelitian yang dilakukan adalah metode penelitian deskriptif Kualitatif .

Data dalam penelitian ini adalah data verbal mengenai budaya lampung. Pengumpulan data dilakukan dengan teknik observasi, wawancara, dan dokumentasi. Teknik Observasi dilakukan dengan mengamati budaya lampung baik dalam upacara-upacaranya, bangunan, Aksara, Bahasa, Pakaian, dll. Teknik wawancara dilakukan dengan tetua adat untuk memperoleh hal-hal yang berkaitan dengan budaya lampung. Teknik dokumentasi dilakukan dengan mempelajari tulisan-tulisan, buku-buku, dll.

Prihatini menyatakan bahwa "setelah data terkumpul, data dianalisis berdasarkan (1) konten budaya lokal apa saja yang diintegrasi dalam teks bacaan, (2) pengintegrasian dilakukan pada ranah apa saja, dan (3) bagaimana cara pengintegrasian budaya lokal itu dilakukan" (Prihatini, 2015). Analisis data dilakukan dalam penelitian ini merujuk pendapat Prihatini, tetapi disesuaikan dengan relevansi penelitian ini. Selain itu pengintegrasian dilakukan tidak hanya kedalam buku tetapi juga dalam proses pembelajaran. Dengan demikian dalam penelitian ini setelah data dikumpulkan maka analisis data dilakukan dengan cara (1) mengidentifikasi konten budaya Lampung apa saja yang diintegrasi, (2) bagaimana cara pengintegrasian budaya Lampung dilakukan dalam Buku Himpunan dan Pembelajaran. Analisis data dilakukan dalam beberapa tahap, yaitu (1) reduksi data, (2) penyajian data, serta (3) penarikan kesimpulan dan 
verifikasitemuan (Miles, \& Huberman, 1992).

\section{HASIL DAN PEMBAHASAN}

Hasil dan Pembahasan penelitian akan diuraikan sebagai berikut.

\section{Konten Budaya Lampung yang akan diintegrasikan}

Data konten budaya lampung telah dikumpulkan melalui berbagai cara yaitu observasi, wawancara, dan dokumentasi. Adapun data yang telah dikumpulkan dikategorikan agar memudahkan dalam analisis dan pengintegrasian dalam buku himpunan dan pembelajaranya. Beberapa konten budaya Lampung sebagai berikut.

a. Rumah Tradisional

Rumah adat lampung disebut dengan Nuwow Sesat. Rumah tradisonal lampung terdiri dari 3 jenis yaitu Sesat Balai Agung, Nuwow Balak, dan Nuwow Lunik.

b. Pakaian Adat Lampung

Pakaian adat Lampung sering dikenakan pada saat upacara adat contohnya pada saat upacara pernikahan. Kain dalam pakaian adat lampung yang populer disebut kain tapis. Ada beberapa aksesoris yang melekat dalam pakaian adat lampung seperti Kalung Papan Jajar, Kalung Buah Jukum, Selempeng Pinang, Ikat Pinggang, Gelang Burung, Gelang Kano Gelang Bibit, dan Siger.

c. Alat Musik Lampung

Lampung memliki alat musik yang menjadi ciri khas budaya lampung. Beberapa alat musik lampung yaitu: Gendang, Cetik, Serdam, dan Harmonium.

d. Upacara Adat Lampung

Beberapa upacara adat lampung yaitu Begawi, Djujor, Tayuhan, Balimau, Ngumbai Lawok, dan Ngambabekha. e. Nilai-nilai Kearifan Lokal Lampung Masyarakat lampung memiliki kearifan lokal yang unik yang disebut dengan Piil Pesenggiri, dimana di dalamnya terkait kehormatan diri yang muncul karena kemampuan mengolah pikiran dan perilaku secara dewasa. Piil Pesinggiri merupakan suatu keutuhan dari empat unsur yaitu; Juluk adek/Adok (dalam kehidupan hendaklah terprogram, agar mencapai keberhasilan), nemui nyimah (ramah, terbuka, dan saling menghargai terhadap orang lain), nengah nyappukh (prinsip suka bergaul, terjun dalam masyarakat, kebersamaan, kesetaraan dalam kehidupan bermasyarakat, atau dengan kata lain menolak sikap individualisme), dan sakai sambayan (berprinsip kerjasama, atau kebersamaan dalam masyarakat tanpa membedakan latar belakang yang dimiliki

\section{Pengintegrasian Budaya Lampung dalam Buku Himpunan}

Sebelum

dilakukan

pengintegrasian budaya lampung dalam buku himpunan, akan dijelaskan terlebih dahulu materi himpunan. Materi yang yang biasanya dikaji dalam buku himpunan yaitu 1) Himpunan, dengan kajian yaitu Sejarah Himpunan; Definisi himpunan; representasi Himpunan; Krdinalitas Himpunan; Himpunan Kosong; Himpunan Bagian; kesamaan himpunan; ekuivalensi; himpunan saling lepas; himpunan kuasa; Operasi pada himpunan ( irisan, gabungan, komplemen, selisih, gabungan, dan perkalian); dll. Selain itu juga dibahas terkait konsep Relasi dan fungsi.

Pengintegrasian ini menggunakan gagasan dari Prihantini yaitu dalam 
melakukan Pengintegrasian budaya lampung dalam buku himpunan dilakukan dengan berbagai cara yaitu 1) pengintegrasian budaya lampung dalam permasalahan himpunan, 2) Butir perenungan, 3) konsep himpunan yang dikaitkan dengan kearifan lokal lampung (Prihatini, 2015). Berikut ditampilkan bentuk integrasi budaya lampung dalam permasalahan himpunan.

a. Pengintegrasian rumah tradisional Lampung dalam mata kuliah Himpunan Berikut disajikan beberapa bentuk integrasi dari rumah tradisional lampung dalam mata kuliah himpunan.

Materi: Definisi Himpunan

Bentuk pengintegrasian:

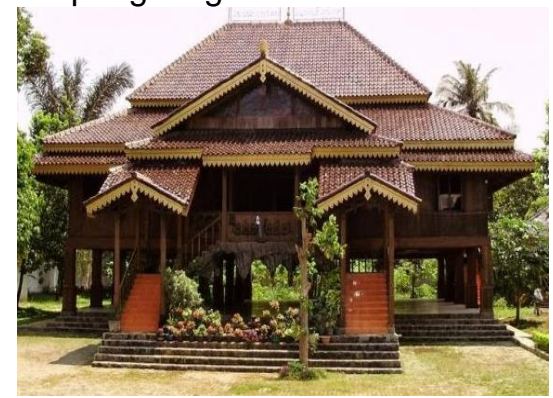

Gambar 1. Rumah Adat Lampung

Gambar tersebut adalah gambar Nuwo sesat (rumah adat lampung). Perhatikan bentuk atap rumah tersebut. Kelompokkanlah bentuk atap rumah tersebut berdasarkan bentuk seginya?

Materi: Himpunan Bagian (subset)

Bentuk Pengintegrasian:

Nuwo sesat (rumah adat lampung) biasanya terdiri Pusiban, anjungan, tetabuhan, Gajah merem, Ijan Geladak, dan kebik tengah. Gambarkan pernyataan tersebut dalam diagram Venn?

Materi: Himpunan

Bentuk Pengintegrasian:

Anda dapat mempelajari atau mengobservasi rumah adat lampung (nuwo sesat) yang ada disekitar anda. Renungkan kemudian buatlah permasalahan himpunan yang ada kaitanya dengan rumah adat lampung?

b. Pengintegrasian pakaian adat Lampung dalam mata kuliah Himpunan

Berikut disajikan beberapa bentuk integrasi dari pakaian adat Lampung dalam Mata kuliah Himpunan.

\section{Materi: Relasi}

Bentuk pengintegrasian:

Dalam pakaian adat lampung, pakaian lakilaki terdiri dari 8 aksesoris yaitu Kopiah emas berujim, kalung buah jukum, kalung papan jajar, slempang pinang, bulu serti, gelang burung, gelang kano, dan gelang bibit. Aksesoris pakaian adat perempuan terdiri dari siger, Seraja Bulan, Subang, kalungbuah jukum, kalung papan jajar, kalung ringgit, gelang kano, gelang burung, gelang bibit, gelang duri, selempang pinang, dan bulu serti. Jika $A=\{$ Pakaian laki-laki, pakaian perempuan\} dan Himpunan B adalah aksesoris pakian lakilaki dan perempuan. Jika relasi dari $A$ ke $B$ menyatakan "Aksesoris dari". Nyatakan relasi antara himpunan $\mathrm{A}$ ke himpunan $\mathrm{B}$ ?

Materi: Refresentasi dan operasi Himpunan

Bentuk pengintegrasian: 
Misalkan Himpunan A adalah aksesoris yang digunakan dalam pakaian adat lakilaki dan Himpunan B adalah aksesoris yang digunakan dalam pakaian adat wanita.

(1). Gambarkan himpunan A dan himpunan $B$ dalam diagram Venn

(2). Tentukan $A \cap B$

(3). Tentukan $A \cup B$

(4). Tentukan $A-B$

(5). Tentukan B-A

Materi: Himpunan

Bentuk pengintegrasian:

Anda dapat mempelajari atau mengobservasi pakaian adat lampung (termasuk kain tapis) yang ada disekitar anda. Renungkan kemudian buatlah permasalahan himpunan yang ada kaitanya dengan pakaian adat lampung?

c. Pengintegrasian Alat musik tradisional Lampung dalam mata kuliah Himpunan Berikut disajikan beberapa bentuk integrasi dari alat musik tradisional Lampung dalam Mata kuliah Himpunan.

Materi: Definisi Himpunan

Bentuk Pengintegrasian:

Lampung memiliki berbagai alat-alat musik tradisional yang dimainkan dengan berbagai cara yaitu Gendang melayu Lampung dimainkan dengan di pukul, Membling dimainkan dengan cara di petik, gamolan dimainkan dengan cara dipukul, terbangan dimainkan dengan cara pukul, khadap dimainkan dengan cara di pukul, Gambus lunik dimainkan dengan cara dipetik, cetik lampung dimainkan dengan cara dipukul, kulintang dimainkan dengan cara dipukul, serdam dimainkan dengan cara ditiup, Harmonium dimainkan dengan cara ditiup. Buatlah Himpunan alat musik tradisional lampung berdasarkan cara memainkannya?

Materi: Relasi dan fungsi

Bentuk Pengintegrasian:

Jika Himpunan A adalah alat-alat musik tradisonal lampung dan B adalah cara memainkan alat musik tradisional lampung. Tentukan

(1). Relasi dari himpunan A ke B?

(2). Nyatakan relasi tersebut dengan diagram panah dan matriks?

(3). Selidiki apakah relasi tersebut merupakan suatu fungsi?

Materi: Himpunan

Bentuk Pengintegrasian:

Anda dapat mempelajari atau mengobservasi alat musik tradisional lampung yang ada disekitar anda. Renungkan kemudian buatlah permasalahan himpunan yang ada kaitanya dengan alat musik tradisional lampung?

d. Pengintegrasian Upacara adat Lampung dalam Materi Himpunan

Berikut disajikan beberapa bentuk integrasi dari upacara adat lampung dalam Mata kuliah Himpunan.

Materi: Operasi Himpunan

Bentuk Pengintegrasian:

Begawi adalah upacara adat lampung yang diselenggarakan dalam rangka memberikan gelar adat kepada seseorang. Dalam upacara begawi diketahui sebanyak 15 orang memakai kain tapis, sebanyak 9 
orang memakai kopiah emas, 5 orang memakai kain tapis dan kopiah emas, sedangkan 7 orang tidak memakai kopiah emas atau kain tapis. Tentukanlah

(1). Berapa orang yang hadir dalam upacara tersebut?

(2). Berapa orang yang hanya menggunakan kain tapis?

(3). Berapa orang yang hanya menggunakan kopiah emas?

Materi: Himpunan

Bentuk Pengintegrasian:

Anda dapat mempelajari atau mengobservasi Upacara adat lampung yang ada disekitar anda. Renungkan kemudian buatlah permasalahan/ materi himpunan yang ada kaitanya dengan upacara adat lampung?

\section{e. Pengintegrasian Kearifan lokal Lampung dalam Mata kuliah Himpunan Berikut disajikan beberapa bentuk integrasi dari kearifan lokal tradisi Lampung dalam Mata kuliah Himpunan.}

Materi: Irisan

Bentuk Pengintegrasian:

Munculnya konflik dan kekacauan diantara masyarakat yang tinggal diprovinsi lampung diperlukan berbagai cara untuk menyelesaikan masalah tersebut. Ruslan menyatakan menyebutkan salah satu cara potensial bagi persoalan tersebut adalah penyelesaiaan dengan pendekatan kearifan lokal lampung yaitu piil pesinggiri dan muakhi (Ruslan, 2018). Prinsip penyelesaiannya memahami adanya perbedaan dan lebih fokus melihat banyaknya persamaan. Prinsip ini dalam teori himpunan ada kaitannya dengan konsep irisan yang jika digambarkan sebagai berikut.

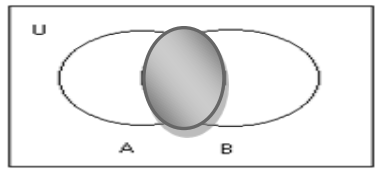

Diagram Venn untuk $A \cap$

Materi: Himpunan

Bentuk Pengintegrasian:

Anda dapat mengkaji atau merenungkan betapa kayanya nilai-nilai luhur dalam kearifan lokal lampung. buatlah permasalahan/ materi himpunan yang ada kaitanya dengan kearifan lokal lampung?

\section{Pengintegrasian Budaya Lampung dalam pembelajaran Himpunan dengan Flatform schoology}

Pengintegrasian budaya lampung dalam pembelajaran himpunan dengan flatform schoology dapat dilakukan dengan berbagai cara yaitu integrasi nilai-nilai kearifan lokal dalam pembelajaran (Wuryandani, 2010). Pengintegrasian nilainilai kearifan lokal dapat dilakukan pada saat: (1) proses penyusunan perangkat pembelajaran;

pembelajaran; (3) pada saat evaluasi pembelajaran (Lestari, 2018), dan (4) integrasi kearifan lokal dalam sarana prasarana pembelajaran (Pingge, 2017).

Dalam pembelajaran himpunan dengan flatform schoology, bentuk pengintegrasian budaya lampung dilakukan dengan cara mengintegrasikan nilai-nilai kearifan lokal pada perangkat pembelajaran yaitu: (1) rencana pembelajaran semester; (2) pada saat pelaksanaan pembelajaran; dan (3) pada saat evaluasi pembelajaran. 
Perlu dijelaskan kembali nilai-nilai kearifan lokal lampung terdiri disebut dengan Piil Pesenggiri, dimana di dalamnya terkait kehormatan diri yang muncul karena kemampuan mengolah pikiran dan perilaku secara dewasa. Piil Pesinggiri merupakan suatu keutuhan dari empat unsur yaitu; Juluk adek/Adok (dalam kehidupan hendaklah terprogram, agar mencapai keberhasilan), nemui nyimah (ramah, terbuka, dan saling menghargai terhadap orang lain), nengah nyappukh (prinsip suka bergaul, terjun dalam masyarakat, kebersamaan, kesetaraan dalam kehidupan bermasyarakat, atau dengan kata lain menolak sikap individualisme), dan sakai sambayan (berprinsip kerjasama, atau kebersamaan dalam masyarakat tanpa membedakan latar belakang yang dimiliki.

Kearifan lokal lampung dalam Rencana Pembelajaran Semester (RPS) diintegrasikan dalam bentuk: (1) buku ajar yang digunakan sudah terintegrasi dengan budaya lampung; (2) menerapkan teknik diskusi kelompok sebagai perwujudan kearifan lokal sakai sambayan dan nengah nyappukh yaitu prinsip kerjasama, kebersamaan tanpa membedakan latarbelakang anggota, dan suka bergaul; dan (3) menerapkan presentasi kelompok sebagai bentuk perwujudan kearifan lokal juluk adok, yaitu prinsip agar kelompok mempersiapkan diri dan melaksanakan presentasi secara sistematis sehingga pembelajaran berjalan dengan baik dan berhasil.

Bentuk integrasi kearifan lokal lampung dalam pelaksanaan pembelajaran dapat dilakukan dengan cara yaitu: (1) membuka ruang diskusi baik luar jaringan (luring) atau dalam jaringan (daring) antar kelompok sebagai perwujudan kearifan lokal nemui nyimah, yaitu prinsip keterbukaan menerima saran atau kritik dari kelompok lain dan menghargai setiap pendapat yang muncul; dan (2) Dosen mengingatkan kepada kelompok/ mahasiswa agar memiliki rasa malu/harga diri dalam hal malu jika belum paham tapi tidak mau bertanya, malu jika tidak ikut aktif selama proses pembelajaran, dan memiliki harga diri yang tinggi dalam hal etika, ilmu, dan akhlak. Hal ini sebagai bentuk perwujudan kearifan lokal lampung Piil pesinggiri yaitu prinsip yang mengajarkan agar memiliki kehormatan diri.

Bentuk integrasi kearifan lokal lampung dalam evaluasi pembelajaran dapat dilakukan dengan cara yaitu penilaian yang dilakukan tidak hanya memperhatikan aspek kognitif tetapi juga aspek afektif. Mahasiswa yang telah berupaya mengimplementasikan nilai-nilai kearifan lokal selama pembelajaran perlu mendapatkan porsi tertentu dalam integral penilaian.

\section{PENUTUP \\ Simpulan}

Lampung memiliki khasanah kekayaan budaya yang dapat dilihat pada rumah adat lampung, Pakaian adat lampung, alatalat musik tradisional, upacara adat Lampung, dan nilai-nilai kearifan lokal lampung. Untuk menumbuhkan kesadaran dan kecintaan mahasiswa terhadap budaya lampung, salah satu cara yang dapat dilakukan adalah dengan mengintegrasikan budaya lampung terhadap pembelajaran. Adapun bentuk pengintegrasian budaya lampung yang 
dapat dilakukan dalam pembelajaran Himpunan dengan flatform schoology yaitu: (1) mengintegrasikan budaya lampung dalam materi himpunan; (2) mengintegrasikan nilai-nilai kearifan lokal dalam pembelajaran dengan flatform schoology.

\section{Saran}

Saran yang diberikan kepada seluruh pendidik adalah agar kiranya dalam pembelajaran peserta didik dikenalkan dengan kebudayaan lokal masing-masing, sehingga kebudayaan lokal akan terjaga dan tidak punah. Bentuk pengenalan itu dapat berupa pengintegrasian dalam pembelajaran.

\section{DAFTAR PUSTAKA}

Aminoto , T., \& Pathoni, H. (2014). Penerapan Media E-Learning Berbasis Schoology Untuk Meningkatkan Aktivitas dan Hasil Belajar Materi Usaha dan Energi Di Kelas XI SMA N 10 Kota Jambi. Sainmatika, 13-29. Diambil kembali dari https://www.neliti.com/id/publicatio ns/221167/penerapan-media-elearning-berbasis-schoologyuntuk-meningkatkan-aktivitas-dan$\mathrm{h}$

Darwanto, \& Sari, N. (2020). Pengintegrasian Soft Skills pada Setiap Pembelajaran. Eksponen, 10(2), 42-49. Diambil kembali dari https://jurnal.umko.ac.id/index.php leksponen/article/view/295

Dinata, K. B. (2018). Inovasi Pembelajaran Aljabar Ring Melalui Lesson Study. Eksponen, 8(1), 53-59. Diambil kembali

dari https://jurnal.umko.ac.id/index.php /eksponen/article/view/141

Dwidayati, N. (2018). Pengintegrasian Etnomatematika Dalam Pembelajaran Berbasis Masalah. Prosiding Seminar Nasional Matematika. 1, hal. 516-521. Semarang: Prisma. Diambil kembali dari https://journal.unnes.ac.id/sju/inde x.php/prisma/article/view/20135

Juraman, S. R. (2014). Pemanfaatan Smartphone Android oleh Mahasiswa IImu Komunikasi dalam Mengakses Informasi Edukatif. ACTA DIURNA KOMUNIKASI, 3(1). Diambil kembali dari https://ejournal.unsrat.ac.id/index. php/actadiurnakomunikasi/article/v iew/4493

Lestari, E. Y. (2018). PERAN STRATEGIS KEARIFAN LOKAL DALAM PENDIDIKAN KARAKTER MELALUI PEMBELAJARAN PENDIDIKAN

KEWARGANEGARAAN DI ERA DISRUPSI. Seminar Nasional Pendidikan dan Kewarganegaraan IV (hal. 194-200). Ponorogo: Universitas Muhammadiyah Ponorogo. Diambil kembali dari http://seminar.umpo.ac.id/index.ph p/SEMNASPPKN/article/view/176

Miles, , B. M., \& Huberman, M. (1992). Analisis Data Kualitatif Buku Sumber Tentang Metode-metode Baru. Jakarta: UIP.

Musafiri, M. R. (2016). Peran Kearifan Lokal Bagi Pengembangan 
Pendidikan Karakter Pada Sekolah Menengah Atas. Darussalam, 119. Diambil kembali dari https://ejournal.iaida.ac.id/index.p $\mathrm{hp} /$ darussalam/article/view/2

Pingge, H. D. (2017). Kearifan Lokal dan Penerapannya di Sekolah. Jurnal edukasi Sumba, 128-135. Diambil kembali dari http://jurnalstkipweetebula.ac.id/index.php/jes/artic le/view/27

Prihatini, A. (2015). Pengintegrasian Konten Budaya Lokal Dalam Buku Tematik Pegangan Siswa Kelas $\mathrm{V}$ Sekolah Dasar. LINGUA, 12(2), 173-186. Diambil kembali dari https://lingua.soloclcs.org/index.ph p/lingua/article/view/26

Ruslan, I. (2018). Dimensi Kearifan Lokal Masyarakat Lampung sebagai Media Resolusi Konflik. Kalam, 12(1), 105-126. Diambil kembali dari

http://103.88.229.8/index.php/KAL AM/article/view/2347

Timbowo, D. (2016). Manfaat Penggunaan Smartphone sebagai Media Komunikasi (Studi pada Mahasiswa Jurusan IImu Komunikasi Fakultas IImu Sosial dan Politik Universitas Sam Ratulangi). ACTA DIURNA KOMUNIKASI. Diambil kembali dari

https://ejournal.unsrat.ac.id/index. php/actadiurnakomunikasi/article/v iew/11719/11312

Wahyudi, I. (2017). Pengembangan Program Pembelajaran Fisika SMA Berbasis E-Learning dengan Schoology. 6(2), 187-199. Diambil kembali

dari http://ejournal.radenintan.ac.id/ind ex.php/al-biruni/article/view/1850 Wuryandani, W. (2010). Integrasi Nilai-nilai Kearifan Lokal dalam Pembelajaran untuk Menanamkan Nasionalisme di Sekolah Dasar. Proceding Seminar Nasional Lembaga Penelitian UNY (hal. 110). Universitas Negeri Yogyakarta. 